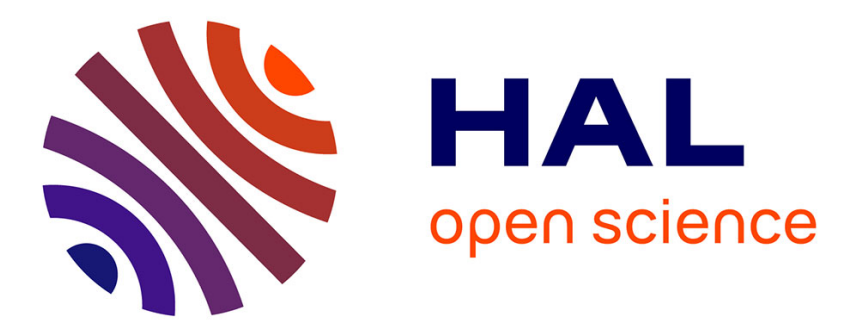

\title{
Low Temperature Electronics for Space Applications
}

E. Armandillo

\section{To cite this version:}

E. Armandillo. Low Temperature Electronics for Space Applications. Journal de Physique IV Proceedings, 1996, 06 (C3), pp.C3-177-C3-185. 10.1051/jp4:1996327 . jpa-00254245

\section{HAL Id: jpa-00254245 https://hal.science/jpa-00254245}

Submitted on 1 Jan 1996

HAL is a multi-disciplinary open access archive for the deposit and dissemination of scientific research documents, whether they are published or not. The documents may come from teaching and research institutions in France or abroad, or from public or private research centers.
L'archive ouverte pluridisciplinaire HAL, est destinée au dépôt et à la diffusion de documents scientifiques de niveau recherche, publiés ou non, émanant des établissements d'enseignement et de recherche français ou étrangers, des laboratoires publics ou privés. 


\title{
Low Temperature Electronics for Space Applications
}

E. Armandillo

European Space Agency, P.O. Box 299, 2200 AG Noordwijk, The Netherlands

\begin{abstract}
To meet the requirements for very high sensitive detection posed by a number of space programmes, such as in Radioastronomy or Earth observation, the European Space Agency has been developing low temperature sensors comprising superconducting detectors from the $\mathrm{mm}$ to the $\mathrm{X}$ band, SQUID magnetometers and gradiometers. This paper will review the technology status and results achieved today.
\end{abstract}

\section{INTRODUCTION}

A number of space programmes presently under consideration at the European Space Agency (ESA), require cryogenically cooled devices to fulfill the observation/mission objectives. Example of cryogenic devices presently being considered for use in future space programmes include, superconducting tunnel junctions, photoconductors, bolometers, for radiation detectors, and SQUID (Superconducting-Quantum-InterferenceDevice)-based sensors for magnetometry and gravity gradiometry.

In preparation of advanced instrumentation as needed by future space programme, the Agency has been carrying out a research and development programme aimed at the demonstration of the feasibility of the critical components and to the predevelopment of technology demonstrators. In a number of cases these technology demonstrators have been tested in airborne flights or scientific campaigns or used in pilot experiments in validation of the design concept and performance capabilities prior to the spaceborne deployment.

\section{SUPERCONDUCTING SENSORS}

\subsection{Low Temperature Superconducting Mixers}

\subsubsection{SIS Tunnel Junction mixers}

ESA fourth cornerstone scientific mission, FIRST (Far Infrared and Submm Space Telescope), scheduled for launch in the first decade of the years 2000', is intended as a multipurpose Astronomy facility covering the spectral range comprised between $1 \mathrm{~mm}$ and 100 micron. FIRST payload comprises, among alia, a total of four incoherent and heterodyne cryogenic instruments, based upon photoconductors, bolometers, and SIS tunnel junctions mixers. 
Superconducting-Insulator-Superconducting (SIS) tunnel junctions are the most sensitive radiation detector, allowing single photon detection. SIS junctions consist in a base superconducting electrode, a thin layer of insulator (typically $10 \AA$ ) and a top superconducting electrode which can be of the same or different material than the base electrode. In the superconductors the electrons are paired (Cooper pair) and in normal conditions of bias and with no applied field, cannot cross the insulator. Under presence of a radiation field, single particles (electrons) can acquire through (multi)photon excitation sufficient energy to tunnel through the barrier to unoccupied states in the other electrode. This tunneling current occurs abruptly for electron energy corresponding to the superconductor energy gap and produces a strong non-linearity in the I-V curve. This nonlinearity, the strongest in nature, can be used for detection purposes and can produce a very efficient mixing process which permits, in principle, to detect a single quantum of radiation.

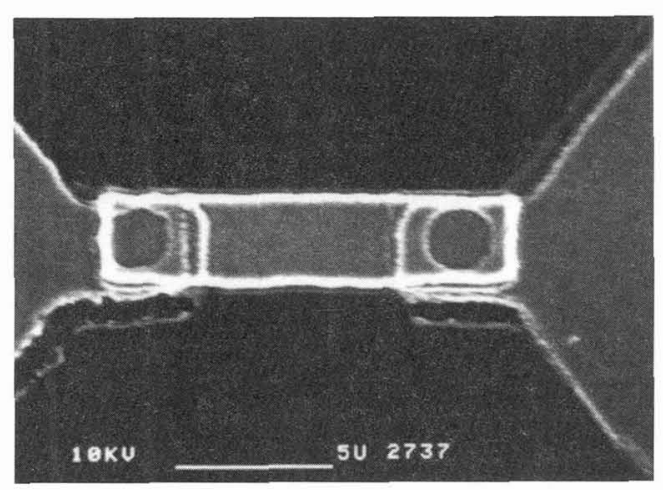

a)

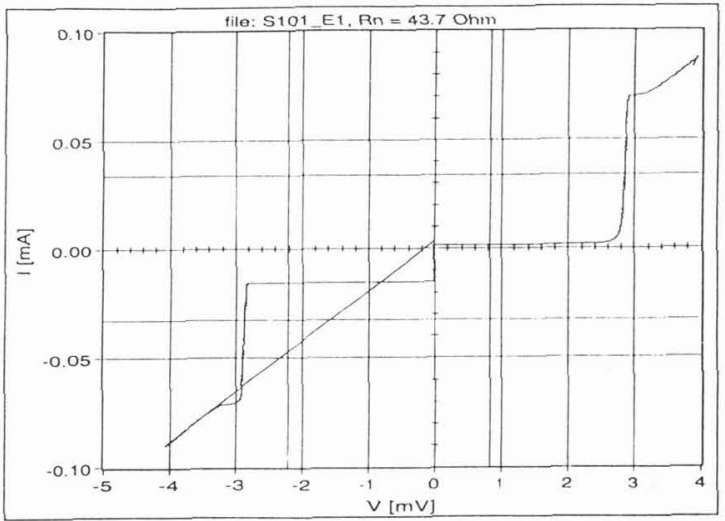

b)

Figure 1 : a) Close-up look at a $\mathrm{Nb}-\mathrm{Al}_{2} \mathrm{O}_{3}-\mathrm{Nb} 1 \mu^{2}$ SIS junction-pair. b) Measured I-V curve

In the far-infrared, heterodyne detection allows very high spectral and spatial resolution, and quantum-noise limited detection is possible. To exploit the benefits offered from heterodyne detection at submm wavelengths, ESA has been engaged over the past decade in a technology programme aimed at the development of superconducting heterodyne receivers up to about 100 micron.

Up today ESA heterodyne SIS mixers have been fabricated up to about 300 micron (1 $\mathrm{THz}$ ). Two types of SIS mixers technology have been developed, waveguide technology, where radiation is coupled through a horn on the SIS junctions, which are embedded in a waveguide, and open-structure technology where radiation is coupled through a planar antenna feed containing the SIS junctions. 
Two types of superconductor materials are being investigated: Niobium, with a gap frequency of about $700 \mathrm{GHz}$ and $\mathrm{NbN}$ with a gap frequency of $1300 \mathrm{GHz}$. Niobium technology has been the most extensively studied and had led to the best results in terms of noise performance, within a factor of 5 from the quantum limit ! Operation above the gap frequency of the base electrode has been demonstrated by using normal metal striplines in place of superconducting striplines. In fact above the gap the superconductor is resistive and exhibit ohmic losses superior to metals such as Aluminum or Gold.

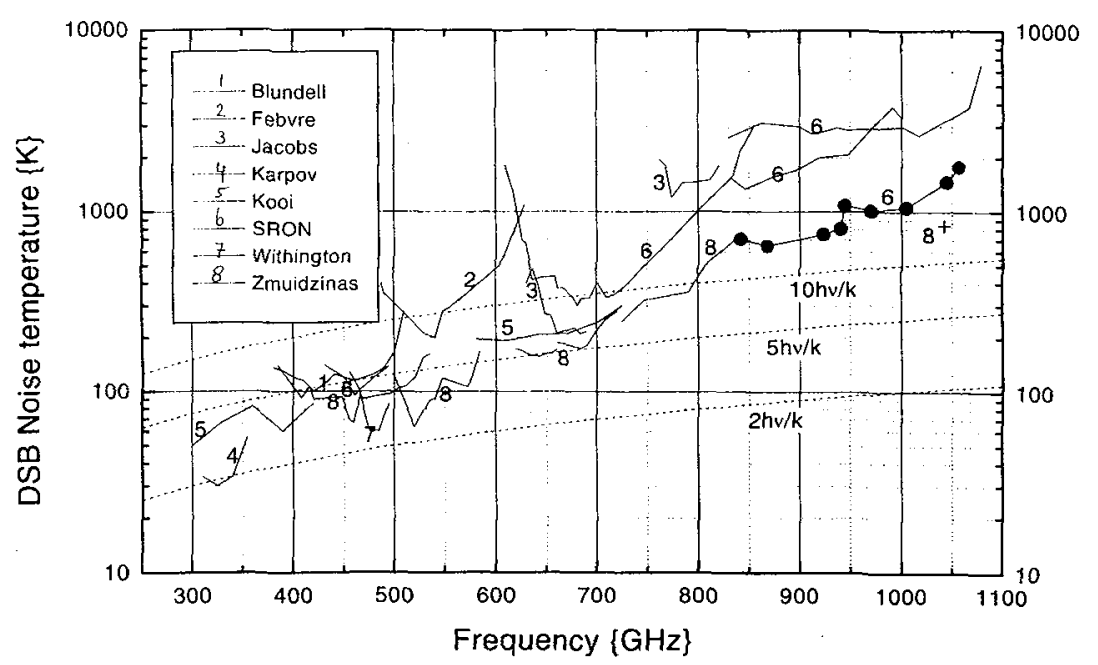

Figure 2: Sensitivity of SIS Heterodyne Receivers above $300 \mathrm{GHz}$

Operation of a tunnel junction should in principle be possible up to twice the gap frequency, albeit at reduced performance, provided that the increasing ohmic losses can be reduced. $\mathrm{NbN}$, compared to $\mathrm{Nb}$ exhibits a higher gap voltage, therefore allows to work at higher frequency, however the quality of $\mathrm{NbN}$ junctions is not yet comparable to that achievable with $\mathrm{Nb}$. Quantum limited detection in the $2-3 \mathrm{THz}$ range is today a challenging task, being dependent on the availability of suitable high quality tunnel junctions. $\mathrm{NbN}$ is a possibility being pursued by ESA; high temperature superconductors could allow to operate a heterodyne mixer well in the $\mathrm{THz}$ range, but so far no suitable tunnel junctions have been produced.

\subsubsection{Integrated Planar Superconducting Receivers}

In the mixers type discussed above, the local oscillator power is provided externally by a combination of a frequency stabilized, tunable Gunn oscillator operating at a frequency of 80-100 MHz, and a combination of a frequency multiplier-chain based upon GaAs varactors. Power levels of about $100 \mu \mathrm{W}$ have been obtained at around $1 \mathrm{THz}$. Another technology being pursued by ESA is a fully integrated heterodyne receiver, whereby the 
local oscillator power is provided by tunnel junctions by means of the Josephson oscillations, which naturally occur in a tunnel junction under voltage bias.

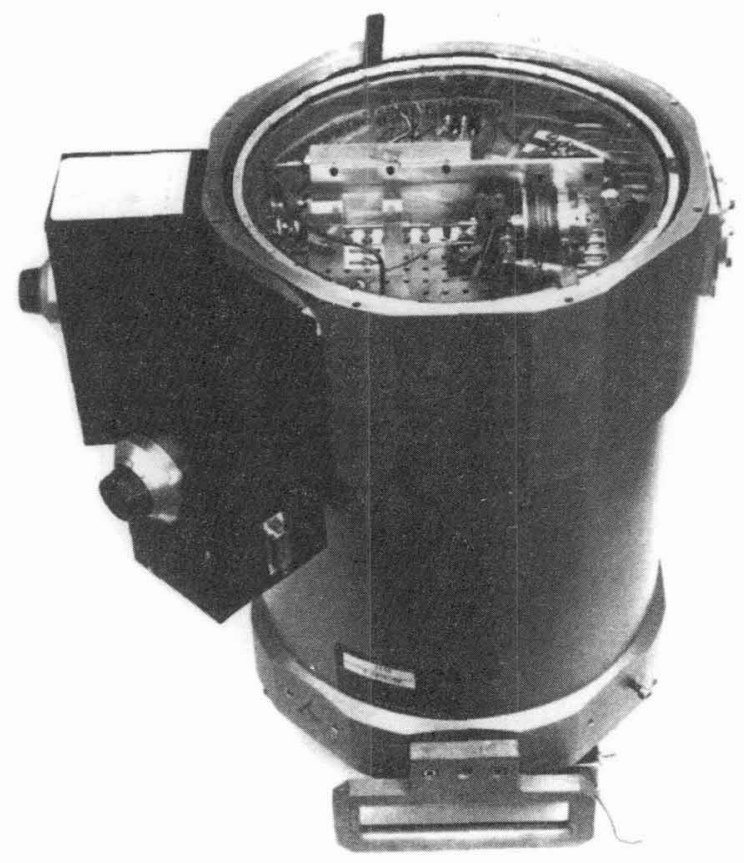

Figure 3: Waveguide SIS $1000 \mathrm{GHz}$ Mixer in Helium Dewar

Presently an array of 9 integrated submm mixers is under development in $\mathrm{Nb}$ technology. The new concept pursued features flux-flow oscillators, planar antenna feed and SIS junctions all made on the same Niobium chip. This leads to a very compact arrangement with imaging capabilities, particularly suitable to map extend astronomical sources.

The results achieved so far in the frequency range 400 to $700 \mathrm{GHz}$ indicate a noise performance comparable with that achievable with separate local oscillator, and a wider tuning range.

\subsection{Ultra-low temperature Superconducting Photon Detector Array}

High quality, Niobium based superconducting tunnel junctions, when operated at very low temperature to suppress subgap current, have been successfully demonstrated to work as single photon detector for visible/ UV wavelengths. 
At these short wavelengths each photon is absorbed in a thin layer of the top electrode breaking many Cooper pairs, the current produced in the external circuit is a linear function of the oncoming photon flux.

Recent developments conducted at ESA-ESTEC, have shown that at a working temperature of $0.4 \mathrm{~K}$, single photon counting up to $470 \mathrm{~nm}$ is possible, with a wavelength resolution of about $20 \%$. These devices have shown excellent energy linearity, and high quantum efficiency. Work is now in progress to build a optical camera based upon this new concept which will offer substantial advantages over semiconductor based detectors as the CCD. In particular the time resolution of the SIS devices appears very good, limited only by the quasi-particle lifetime of about 1 microsecond.

\subsection{High Temperature Superconducting Sensor}

The European Space Agency is involved in a technology programme aimed at the assessment of feasibility of high temperature superconducting sensors for space. Two main applications have been identified and are being investigated for potential applications in ESA programmes: SQUID-based sensors and far-ir bolometers.

\subsubsection{High Temperature Superconductor Bolometer}

Upper atmosphere measurement of $\mathrm{OH}$ is being studied by the Agency for environmental applications. A Fabry-Perot spectrometer, with cooled bolometers, is being considered a possible instrument for future environmental satellites.

The performance requirements posed for $\mathrm{OH}$ detection, lead to a bolometer diameter of about $1 \mathrm{~mm}$ with a NEP of better than $3 \times 10^{-12}$. The development of a GBCO $\left(\mathrm{GdBa}_{2} \mathrm{Cu}_{3} \mathrm{O}_{7}\right)$ membrane, transition-edge bolometer is presently under way. The technology concept being pursued is based on the use of $\mathrm{Si}_{3} \mathrm{~N}_{4}$ membrane since very low thermal conductance and capacitance is possible with this material.
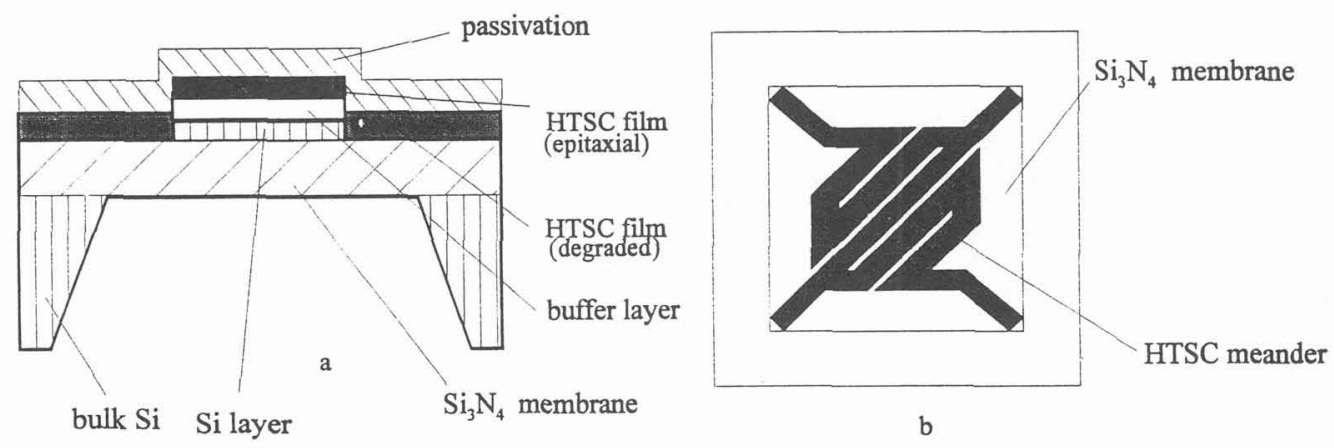

Figure 4: Structure of transition edge bolometer on $\mathrm{Si}_{3} \mathrm{~N}_{4}$; a) cross section, b) top view 
Two main technology routes are being investigated. The first is based on the production of the GBCO thermometer on an epitaxial layer of silicon carried by a membrane supported by $\mathrm{Si}_{3} \mathrm{~N}_{4}$ beams; the second is based on the technology transfer process whereby a GBCO thermometer is fabricated on a pre-fabricated $\mathrm{Si}_{3} \mathrm{~N}_{4}$ membrane carried by a $\mathrm{Si}_{3} \mathrm{~N}_{4}$ beams.

\subsubsection{SQUID Devices and Applications}

SQUID-sensors are the most sensitive detectors of magnetic field and displacement today available. The Agency is considering the use of SQUID-based sensors for possible applications in solid Earth research and Planetology for the measurements of gravity gradient and magnetic field. Low temperature SQUID-based devices are well established as magnetometers, and as brain or heart sensors in medicine.

When compared to the low temperature counterpart, SQUID sensors based on high temperature superconductors are still at a research stage, however there is interest in this technology for space applications since it can provide high enough sensitivity, ultimately limited by the operating temperature, in a regime which does not require a cryostat but where mechanical coolers offer good performance and are space qualified.

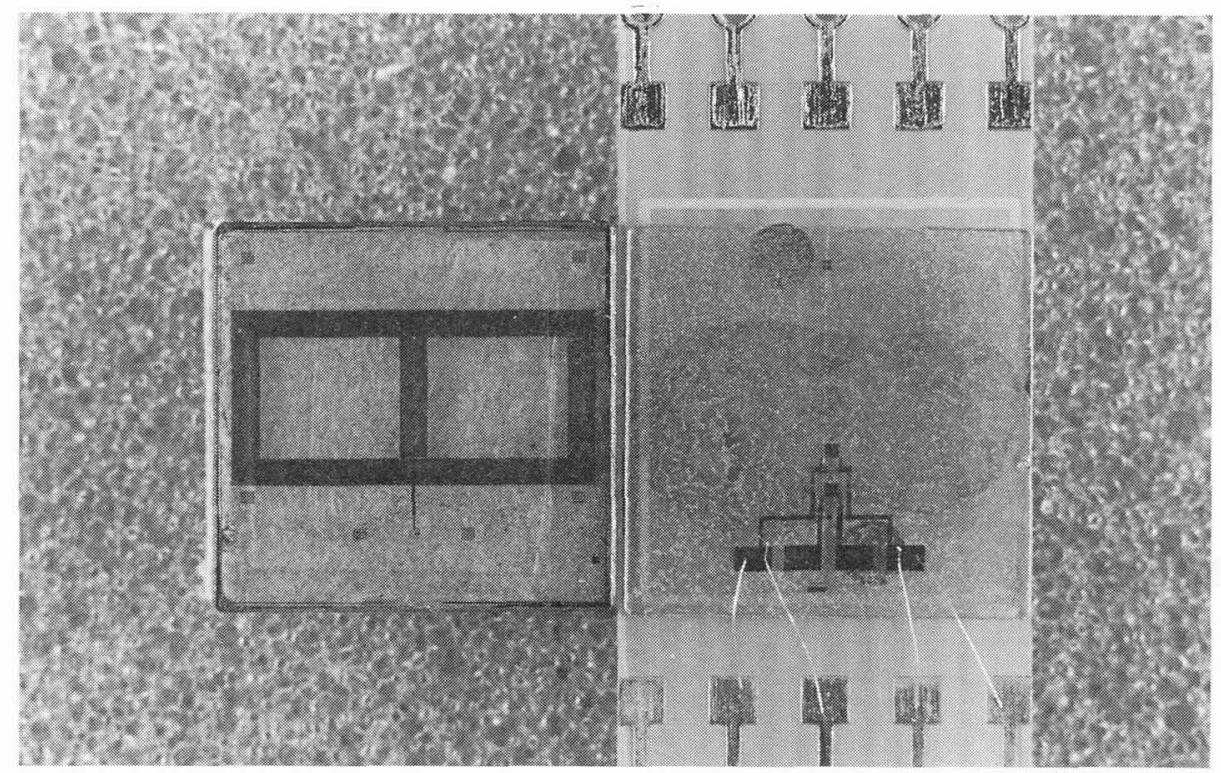

Figure 5: YBCO Gradiometer-SQUID 
Within its technology programme, ESA has investigated the feasibility of fabricating high temperature superconductor SQUID, and has also conducted a conceptual design of a gravity gradiometer for Earth observation.

For Earth gravity gradiometer applications, the sensitivity required is around 0.001 Eotvos $/(\mathrm{Hz})^{1 / 2}$, down to $0.1 \mathrm{~Hz}$. Predevelopment of $\mathrm{YBCO}$-based $\left(\mathrm{YBa}_{2} \mathrm{Cu}_{3} \mathrm{O}_{7}\right)$ gradiometer SQUIDs has been successfully completed. Two technology approaches have been followed: a flip chip design, with the SQUIDs and pick-up coils on different chips, and a monolithic design with both SQUIDs and pick-up coils fabricated on the same chip.

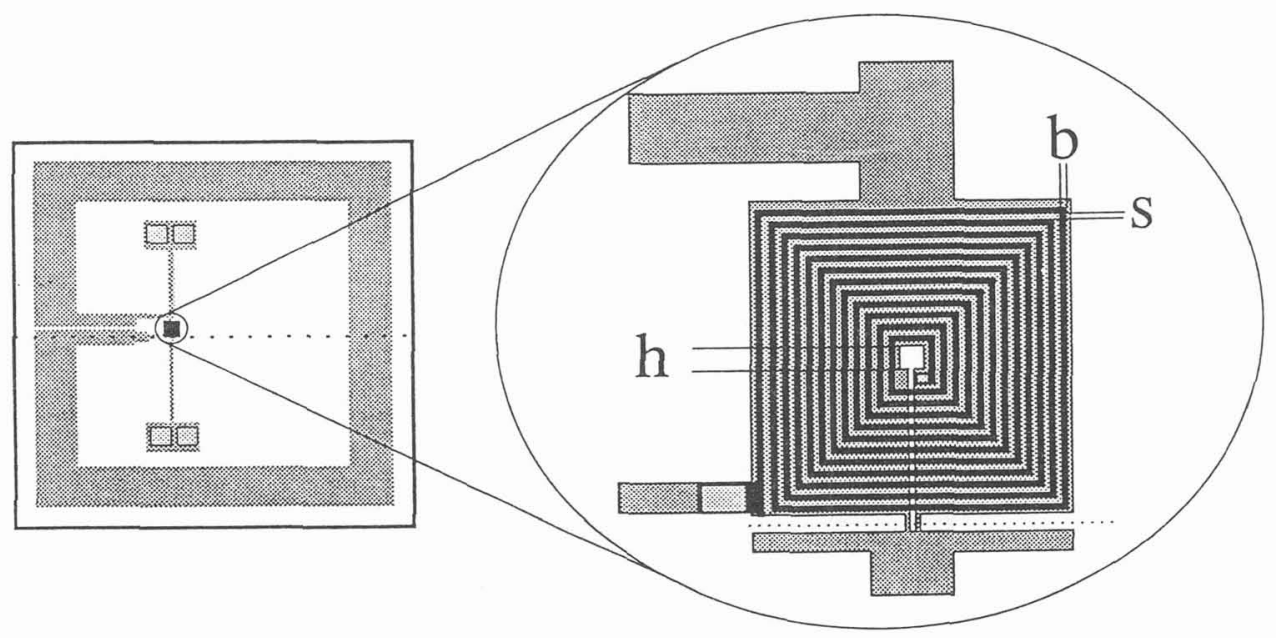

Figure 6: Schematic topview of monolithic flux transformer coupled SQUID magnetometer

The low frequency (1/f) noise has been drastically reduced by means of a current modulation scheme. The field sensitivity achieved with the flip-chip design, 0.1 $\mathrm{pT} /\left(\mathrm{Hz}^{1 / 2}\right)$, is comparable to the low temperature counterpart of commercially available SQUID magnetometers. The fabrication of a fully integrated device presents still a challenging task with respect to the flip chip design.

\section{LOW TEMPERATURE DEVICES}

\subsection{Blocked-Impurity band Si:P and Ge-Ga Stressed Detectors}

As an alternative to conventional bulk $\mathrm{Si}: \mathrm{P}$ and $\mathrm{Ge}: \mathrm{Ga}$ detectors, ESA has been investigating and manufacturing Si:P and Ge:Ga blocked impurity band detectors (BIB's). These detectors are based upon light detection in a thin, highly doped, sensitive layer. They feature less radiation sensitivity, increased spectral coverage, less cross-talk, higher stability after irradiation than standard photoconductors.

BIB's are ideal detectors for the realization of large arrays with FIR response down to 250 microns. Si:P BIB's have been also successfully flown in the Kuyper aircraft 
observatory. More recently the BIB technique has been applied to the production of $\mathrm{Ge}: \mathrm{Ga}$ based devices. Array size of $4 \times 10$ and $32 \times 32$ are being now developed. Their wavelength coverage should extends to 250 micron, and should replace the more known stressed $\mathrm{Ge}: \mathrm{Ga}$ detectors. Stressed $\mathrm{Ge}: \mathrm{Ga}$ are also being developed under ESA contracts.

\begin{tabular}{|c|c|}
\hline $\begin{array}{l}\text { Detector specifications } \\
\text { Detector size }\left(\mathrm{mm}^{2}\right)\end{array}$ & Configuration \\
\hline $\begin{array}{l}1 \times 1 \\
0.4 \times 0.4 \\
0.3 \times 0.3 \\
0.2 \times 0.2\end{array}$ & $\begin{array}{l}\text { single detectors } \\
4 \times 10 \text { element arrays } \\
32 \text { element linear array } \\
32 \text { element linear array }\end{array}$ \\
\hline $\begin{array}{l}\text { Operational and performe } \\
\text { bias voltage } \\
\text { operation temperature } \\
\text { spectral response } \\
\text { readout } \\
\text { readout frequency } \\
\text { dark current } \\
\text { current responsivity } \\
\text { NEP } \\
\text { uniformity of array }\end{array}$ & $\begin{array}{l}\text { ance figures of a typical Si:P BIB detector: } \\
0.2 \cdot 2 \mathrm{~V} \\
4.2 \mathrm{~K} \\
10-30 \mu \mathrm{m} \\
\mathrm{TIA} \text { and cryogenic VLSI } \\
10 \mathrm{HZ} \text { (chopped) } \\
\text { not available } \\
2-4 \mathrm{~A} / \mathrm{W} \\
5 \times 10^{-17} \text { to } 5 \times 10^{-18} \mathrm{~W} / \mathrm{J} \mathrm{Hz} \text { at } \mathrm{Q}_{\mathrm{BG}}<10^{8} \mathrm{phot} / \mathrm{cm}^{2} \mathrm{~S} \\
<75 \%\end{array}$ \\
\hline
\end{tabular}

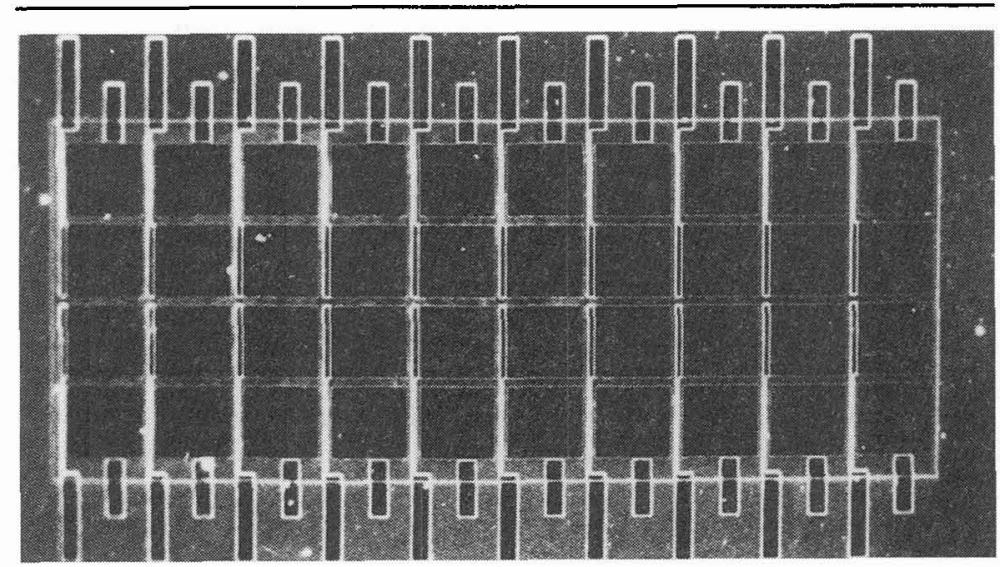

Figure 7: Detail of BIB detector

A detector array of $16 \times 16$ stressed $\mathrm{Ge}: \mathrm{Ga}$ is being developed to meet the requirement of the FIRST astronomical satellite. Both BIB's and stressed $\mathrm{Ge}: \mathrm{Ga}$ far-ir detectors operate at a temperature of about $1.5 \mathrm{~K}$. 


\subsection{GaAs Schottky Receivers}

ESA has also been developing over the past years cooled $(80 \mathrm{~K}) \mathrm{GaAs}$ Schotty receivers for application in atmospheric physics and radioastronomy. This technology effort has covered the following critical components: GaAs diodes, $80 \mathrm{~K}$-cooled submm mixers and quasi-optics, cooled HEMT IF amplifier, solid-state local oscillators and, both wide-band $(1 \mathrm{GHz})$ acousto-optic spectrometer and high resolution $(300 \mathrm{KHz})$ chirp-transform spectrometer.

Among the highlights, a cooled submm receiver operating in the $600 \mathrm{GHz}$ band for the detection of atmospheric $\mathrm{ClO}$ and $\mathrm{HCl}$, has been successfully flown aboard aircraft in scientific campaigns. More recently a cooled all-solid-state $1 \mathrm{THz}$ Schottky receiver has been successfully built with system noise temperature below $4000 \mathrm{~K}$ (DSB) at $80 \mathrm{~K}$.

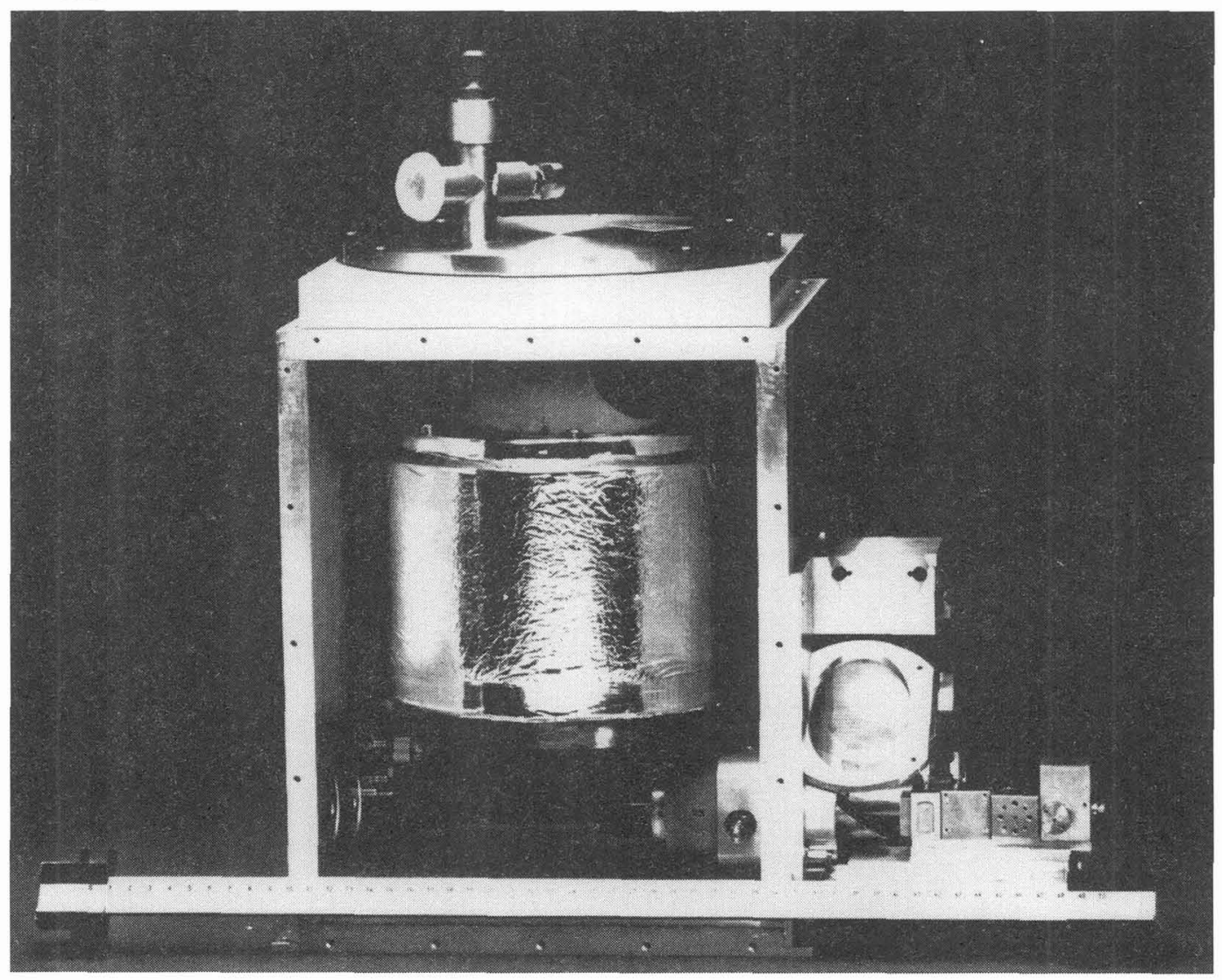

Figure 8: 1 THz Cooled Heterodyne Schottky Receiver 